\title{
"...De puerta en puerta, retomemos la vieja tradición": Reinvención e interpretación de la celebración de Santa Águeda en la diáspora vasca en Barcelona ${ }^{1}$
}

\author{
F. XAVIER MEDina
}

Institut Català de la Mediterrània. Barcelona

\section{RESUMEN}

La celebración del día de Santa Águeda, que ha sido recuperada por los vascos residentes en Barcelona, nos lleva sobre los pasos de un ritual que es recreado tomando como base la tradición vasca, "lo que se hace", en el País Vasco. A través del ritual, se construye un espacio "propio" y significativo para el grupo; que sirve como pauta en la construcción social del nosotros en términos de una etnicidad específica vasca en la diáspora barcelonesa.

\section{SUMMARY}

The day of Saint Agatha has become a holyday for Basques living in Barcelona. Observances reveal a ritual that has been reconstructed on the basis of the Basque tradition, of "what is done" in the Basque country. By means of this ritual, participants construct a significant space "of their own" that provides a pattern with which to attain the social construction of a "we" as a specifically Basque ethnic identity in the diaspora of Barcelona.

Palabras clave: Fiesta. Identidad. Tradición. Migración. País Vasco. Cataluña.

Key words: Religious observances. Identity. Tradition. Migration. Basque Country. Catalonia.

Reza un refrán alavés: "A dos, Candelas, a tres, san Blas, a cuatro, nada y a cinco, Santa Águeda" (López de Guereñu 1988). La fiesta de Santa Águeda

\footnotetext{
${ }^{1}$ Una primera versión más reducida fue presentada como ponencia en las II Jornadas de antropología de las fiestas, organizadas por la Institución Juan Gil Albert de Alicante, en diciembre de 2000. Este artículo corresponde a una versión corregida, aumentada y, en parte, actualizada de la anterior, e incorpora asimismo algunos de los comentarios y aclaraciones que de allí surgieron.
}

RDTP, LVI, 2 (2001): 113-128 
se celebra tradicionalmente en Euskadi (así como en otras comunidades, como Navarra y La Rioja) el día 5 de febrero y es considerada como una de las más tradicionales y populares que se celebran en el país. Del mismo modo, ha sido una fiesta recuperada por los vascos que actualmente residen en Barcelona. La celebración de Santa Águeda nos lleva sobre los pasos de un ritual de origen esencialmente rural y hoy convertido también en urbano. Un ritual que es recreado en el lugar de residencia tomando como base la tradición vasca, "lo que se hace" en el País Vasco.

Como veremos en las líneas que siguen, la celebración de Santa Águeda reconstruye y reformula - reinventa, en definitiva - una tradición. En este sentido, y principalmente, construye un espacio "propio" y significativo para el grupo que sirve como pauta y referencia en la construcción social del nosotros en términos de una etnicidad específica vasca en la diáspora barcelonesa.

\section{ANOTACIONES SOBRE LA CELEBRACión DE SANTA ÁGUEDA}

Santa Águeda, mártir siciliana del siglo III, es considerada, en la mayor parte de España, como patrona de las mujeres. Su leyenda avala este hecho; según la tradición recogida por Nieves de Hoyos (1951: 446): "Prendado por su belleza, el emperador Quinciano quiso rendirla y al no conseguirlo, a pesar de sus ofertas primero y de sus amenazas después, la hace padecer terribles afrentas en el rostro, retorcerla los pechos y después cortárselos a cercén. En la prisión tiene la aparición de San Pedro, el cual hace el milagro de curarla, pero nuevos tormentos la hacen dejar de existir el día 5 de febrero de 252 [...] Es esta santa y virgen la que con acierto han escogido las mujeres como su patrona" ${ }^{2}$. La autora se refiere en su artículo principalmente a Castilla, donde son famosas las celebraciones de Santa Águeda en localidades como Zamarramala (Segovia), donde las mujeres toman el mando del municipio durante un día.

En comunidades como el País Vasco, Navarra y La Rioja, sin embargo, Santa Águeda es también, principalmente, la patrona de los mozos, es decir, de los hombres solteros ${ }^{3}$. Es costumbre en estos territorios que

\footnotetext{
2 Una versión más larga de la leyenda puede encontrarse en La leyenda dorada o leyenda áurea de Jacobo de la Vorágine (1982: 167-170). A ella remitimos para ulteriores consultas y ampliación de información.

${ }^{3}$ Principalmente jóvenes - aunque a veces no tanto-, comprendidos entre la edad que los separa de la infancia y les hace entrar en la adolescencia (usualmente entre los diez y los doce años) y la del matrimonio - sea esta cual sea.
} 
las cuadrillas de jóvenes, especialmente en el medio rural —aunque más tarde se hiciese extensivo también, por supuesto, al ámbito urbano-, salgan a la calle y recorran las casas de los vecinos pidiendo el aguinaldo, lo que habitualmente se llama "pedir la Santa Águeda". En un principio, las cuadrillas recogían un aguinaldo en especie: huevos, chorizos, chistorras..., además de dinero para organizar una cena comunal. Como destaca la misma autora citada con relación a la provincia de Vizcaya: "Gran revuelo de campanas hay en Vizcaya la víspera de la Santa, para lo cual el día antes hacen una colecta de casa en casa, a veces provistos de guitarras, con el fin de recaudar fondos para los tañedores" (Hoyos 1951: 452) ${ }^{4}$.

En La Rioja, como destaca Jociles (1992: 147), los mozos "al grito de ¡Para los quintos! o ¡Para Santa Águeda!, son obsequiados con dinero, huevos, chorizos y otros productos del cerdo [...] Paran también a los automovilistas que van de paso por la localidad, a veces con artes muy drásticas y a cambio de un trago de vino, les solicitan un donativo en metálico". Asimismo, "no deja de sorprender que buena parte de las fiestas [...] de quintos se celebren por Santa Águeda y que esta figura se tome como emblema o bien de ellos o bien de los mozos varones en su conjunto y más cuando no se suele ignorar que está relacionada simbólicamente con lo femenino" (Jociles 1992: 152) ${ }^{5}$. Igualmente, Laburu y Baza (1995: 23) señalan con relación al País Vasco que "puede considerarse Santa Águeda como la principal fiesta entre las que tienen a los mozos como directos protagonistas, hasta el punto de que más de una vez se oye cómo se la denomina así, fiesta de los mozos.

Es tradicional también -y este es el aspecto que más nos interesa destacar aquí - la salida a la calle, pidiendo el aguinaldo, de las corales y

\footnotetext{
${ }^{4}$ Nieves de Hoyos no señala, sin embargo, en el artículo citado, la importancia de la mocería en dicho ritual. Su interés se centra exclusivamente en el papel de las mujeres con relación a esta festividad. En este sentido, mencionará más adelante, también en referencia a Vizcaya, que: "En ese día las mujeres no deben lavar la ropa ni hacer trabajos de horno" (Hoyos 1951: 452).

${ }^{5}$ Aunque no resulte aquí especialmente significativa esta contradicción, podemos exponer, de manera informativa, la explicación que Jociles da a este hecho. Según la autora, la explicación de que Santa Águeda, figura ligada a lo femenino y principalmente a la castidad, sea patrona de los mozos solteros, varones y en los que, además, el elemento más valorado sería su sexualidad activa y en absoluto casta, tiene su correlación en el trato que dichos mozos dan a la Santa, cuya imagen suelen transportar durante la procesión. En el camino, la imagen de Santa Águeda es objeto de burlas diversas y de trato irrespetuoso, solucionando ritualmente la contradicción de dicho patrocinio. Para una mayor información, cf. Jociles (1992).
} 
coros populares -más o menos organizados en este caso, a diferencia de las agrupaciones de mozos-, que cantan las canciones tradicionales del día de Santa Águeda, acompañadas con palos (de azada, habitualmente), con los cuales se marca el ritmo golpeando en el suelo, y faroles o linternas que guían al grupo en la noche ${ }^{6}$. En este caso, los coros recorren las localidades cantando, tanto en espacios públicos como privados y esperando $\longrightarrow$ pidiendo, directamente- como contrapartida una contribución económica o en especie a su interpretación musical. Si la contribución es en especie, ésta puede ser tanto en vino como en comida: huevos, chorizos, chistorras, pan, longanizas... En el ámbito urbano, sin embargo, dichas aportaciones suelen ser principalmente económicas, o, en el caso de que se realicen en especie, lo hacen, sobre todo, en vino.

LA INMIGRACIÓN VASCA EN LA CIUDAD DE BARCELONA. APUNTES INTRODUCTORIOS

Pese a no ser un modelo típico de migración económico-laboral, tal y como se conoce habitualmente -especialmente en las grandes ciudades de un Estado como el español-, el grupo estudiado proporciona, sin embargo, la pauta de comportamiento de un colectivo migrante establecido en un medio urbano en el cual ha reformulado su singularidad étnica, en base, tanto a las características socioculturales que le son propias como al nuevo territorio en el que se encuentra asentado y que, en gran medida, ha convertido en suyo propio.

Un primer dato característico es su relativamente reducido volumen (que en poco excede de las ocho mil personas), siempre en comparación con otros grupos inmigrados, más numerosos, residentes en Barcelona - como el andaluz, el aragonés o el gallego, por ejemplo- Otro factor de interés son sus períodos de llegada a la Ciudad Condal, con puntos álgidos en el lustro $1935-40$ y en la década 1971-80, en obvio contraste con los de individuos pertenecientes a grupos de una más clara tradición migratoria por motivos económico-laborales, con el punto máximo en la década 1961-70.

Podemos ver así que las épocas de llegada de los vascos a Barcelona no se corresponden con las de mayor afluencia migratoria por motivos laborales dentro del Estado español 7 . Igualmente, y de los dos lapsos de

${ }^{6}$ Según Roma (1989: 149) el origen de esta fiesta adaptada al cristianismo, con relación a la iluminación a través de faroles o linternas, se encuentra en la celebración romana de la búsqueda de Proserpina, secuestrada y llevada a los infiernos. Los faroles guiaban a las ánimas, mostrándoles con su luz el camino a seguir.

${ }^{7}$ Hemos desarrollado este aspecto más ampliamente en Medina (2000). 
tiempo señalados, el mayor contingente llegado a la Ciudad Condal desde Euskadi lo encontramos en el primero de ellos (1935-40); período que coincide con las fechas de la Guerra Civil, en que muchos vascos abandonaron su lugar de origen por causas directamente relacionadas con el conflicto bélico y encontraron en Barcelona un enclave privilegiado: por un lado, una ciudad con un tamaño suficientemente considerable que, asimismo, comenzaba a acusar ya las primeras oleadas migratorias; por otro, buenas posibilidades laborales en una economía de amplios antecedentes industriales; y un tercer factor importante en esos momentos de conflictividad: la relativa cercanía de la frontera francesa, ampliamente utilizada durante y después de la conflagración.

Vemos aquí la primera de las causas de llegada a la capital catalana de algunos de los hoy residentes vascos. Pero existe aún otro período -el segundo en importancia- de afluencia de migración vasca hacia Barcelona: la década 1971-80. Aunque la fiebre de la emigración económica ha quedado ya atrás en buena medida en los años anteriores, es aún un período de fuerte inmigración en la ciudad con la llegada, por ejemplo, de un $14,8 \%$ de los hoy residentes andaluces ${ }^{8}$. Podemos observar, sin embargo, que la emigración tradicional (económico-laboral) sufre una disminución importante: en el caso andaluz de un $20 \%$. A pesar de ello, es ahora cuando un nuevo contingente de personas decide su traslado a Barcelona desde el País Vasco.

Observando el mapa urbano barcelonés, y en él las zonas en las que habita un mayor número de inmigrantes vascos, podremos percatarnos de que entre ellas se hallan algunas de las que ostentan una posición económica más elevada. En estas zonas vive un $42,5 \%$ de los miembros del colectivo estudiado y, curiosamente, buena parte de ellos llegaron a Barcelona entre 1971 y 1980. Los motivos laborales por los cuales estos "Otros barceloneses" se encuentran en la ciudad no son los de una búsqueda indiscriminada de empleo sino que, en un gran porcentaje de los casos, es desde el mismo puesto de trabajo que ya se ocupaba en el lugar de origen como se accede, por cambio de destino, a la actual actividad en Barcelona. Este es el caso de varios ejecutivos de empresas, bancos o cajas de ahorros vascos que cuentan con filiales en la capital catalana, así como de otros técnicos y cargos medios que han sido requeridos y trasladados desde Euskadi.

Como ya hemos expuesto, a través de un estudio pormenorizado del grupo vasco podemos encontrar las pautas de comportamiento de un colectivo inmigrado, residente en un marco urbano en el cual redefine

${ }^{8}$ Cf. Padró Municipal. Barcelona, Ajuntament de Barcelona, 1996. 
sus peculiaridades étnicas. El análisis en clave de identidad del ritual de Santa Águeda puede resultarnos revelador a este efecto.

\section{La Santa Águeda vasca en Barcelona}

Siguendo el modelo citado más arriba en relación con las formaciones corales vascas, el coro de la Euskal Etxea -casa y centro cultural vasco- de Barcelona lleva organizando, desde 1996, su propia celebración de Santa Águeda. El hecho de retomar, desde el lugar de residencia de los migrantes, un ritual de fuerte raigambre en el territorio de origen -aunque con nula implantación popular en el de destino en la actualidad ${ }^{9}$ - ha significado para los vascos residentes en Barcelona, tanto una recreación como una reinvención de la tradición, en un nuevo espacio construido y simbolizado "a la medida" de las necesidades del grupo.

El interés particular del análisis de esta celebración radica, asimismo, en el hecho de que podemos asistir al ritual desde su inicio, desde sus primeros momentos, antes incluso de su funcionamiento efectivo, de manera que nos permite observar el proceso y las pautas de su creación y desarrollo dentro del marco más específico de la vida vasca en Barcelona. En las líneas que siguen analizaremos más pormenorizadamente la reinvención y recreación de esta celebración en tanto que ritual, con una estrecha vinculación, como veremos, con una reivindicación específica de la etnicidad vasca en la diáspora barcelonesa.

\section{El nacimiento de un ritual urbano. Apuntes etnográficos}

La iniciativa de la celebración por parte del coro de la Euskal Etxea del día de Santa Águeda nació de la propuesta privada de un grupo de vascos residentes en Barcelona —en el distrito V, Sarrià-Sant Gervasi, en la zona alta de la ciudad, como hemos comentado más arriba-, quienes, queriendo recuperar la tradición que habían vivido en su lugar de origen, hicieron la propuesta a la que entonces, a finales de 1995, era la directora del coro de la Euskal Etxea, para que este último pasase por sus casas a

\footnotetext{
${ }^{9}$ A pesar de que la fiesta se había celebrado en la ciudad de Barcelona hasta el siglo XVIII, señala Joan Amades (1982: 723) que después del año 1835 la capilla de Santa Águeda fue cerrada al culto y la imagen, llevada a la capilla de Sant Jaume, a donde también se trasladó la cofradía de Santa Águeda, aunque sin celebrar ya la fiesta, que se perdió definitivamente a partir de este momento.
} 
cantar en la noche de la víspera de Santa Águeda. Evidentemente, estaban dispuestos a "dar su aguinaldo" por ello, aunque no se llegase en principio a ningún acuerdo previo sobre cantidades concretas.

Tras una primera proposición a los miembros del coro por parte de la directora, estos acordaron - con una cierta ilusión, al haber vivido también en sus localidades de origen las celebraciones de Santa Águeda, por lo que se manifestaron abiertamente dispuestos a colaborar- aceptar la propuesta y preparar una salida para celebrar esta tradición vasca. La junta directiva de la Euskal Etxea dio, asimismo, su permiso para la realización de dicha actividad, en tanto que evocadora o recuperadora de una tradición ciertamente reconocible como vasca y fácilmente situable en la línea de otras manifestaciones festivas de índole semejante, patrocinadas también por la entidad, como la tamborrada de San Sebastián, la celebración del día de Santo Tomás, etc.

De todas formas, se acordó, desde dentro de la agrupación coral, realizar una celebración que fuese más allá del estricto encargo de los particulares que habían promovido la actividad y llevar a cabo, de este modo, un pequeño recorrido por la ciudad, visitando algunos de los locales vascos más renombrados -especialmente restaurantes y bares, previo permiso de cada uno de ellos-, a fin de ampliar el ámbito de la fiesta y hacer partícipes de ella a una mayor parte de la colectividad vasca -además de ampliar la posible recaudación del aguinaldo en esos locales.

Así pues, la coral de Euskal Etxea salió por primera vez a celebrar Santa Águeda la noche del 4 de febrero de 1996, víspera de la Santa. Días antes se habían pedido los permisos a la guardia urbana de los distritos donde se pretendía cantar. Esto hay que hacerlo, legalmente, unos veinte días antes de la salida. Esta primera vez tan sólo se hizo con tres días de antelación, aunque de todas formas se consiguió el permiso provisional para poder salir y cantar en la calle en los dos distritos principales donde se pretendía llevar a cabo el recorrido: los de Ciutat Vella y Sarrià-Sant Gervasi ${ }^{10}$, en pleno centro y en la periferia residencial barcelonesa, respectivamente.

${ }^{10}$ No es en absoluto de extrañar que sean estos dos distritos aquellos en los que se desarrolla la celebración. El de Sarrià-Sant Gervasi es, por un lado, y como hemos tenido ocasión de ver brevemente más arriba, uno de los que cuentan con un mayor número de personas de origen vasco empadronadas y residentes en la ciudad; por otro lado, el distrito de Ciutat Vella es, además de una zona histórica ciertamente significativa para los vascos de Barcelona -durante y después de la Guerra Civilla nueva zona de proliferación de instituciones y de locales - bares y restaurantes, principalmente, aunque también comercios- vascos en la ciudad. 
La directora de la Coral, siguiendo el calendario de fiestas para el ensayo de nuevas canciones, había comenzado a preparar los temas tradicionales de Santa Águeda, una vez pasadas las fiestas de Navidad, ya en enero de 1996. En el segundo ensayo tras las fiestas, el coro dispuso ya de una adaptación de una versión popular del tema tradicional de Santa Águeda para ser ensayada. La letra de esta versión, en euskera ${ }^{11}$, es la siguiente:

\section{SANTA YAGEDA}

Santa Yageda bezpera degu

Euskalherriko eguna,

Etxe guztiak kantuz pozteko, Aukeratu adeguna.

Zori on etxe ontako denoi Oles egitera gatoz,

Aterik ate oitura zarra

Aurten berritzeko asmoz.

Santa Yageda.

Santa maitea gaur artu degu Gure bideko laguna,

Aren laguntzatz betegentza

Keegun ontako jarduna.

Santa Yageda,

Santa Yageda.

Se acordó desde un principio que el primer lugar donde se cantase y desde el cual se iniciase el recorrido, fuese el propio restaurante de la Euskal Etxea. Al mismo tiempo, para poder salir y cumplir con la tradición, se compraron los palos para golpear en el suelo acompañando el ritmo de la música cantada. Se trataba concretamente - como manda la tradición - de mangos de azada, que uno de los miembros del coro se encargó de adquirir.

En lo que respecta a la indumentaria, todos los miembros del coro, hombres y mujeres, tenían que ir de negro, con combinación de otras

${ }^{11}$ La traducción de la letra es la que exponemos a continuación: «Hoy es el día de Santa Águeda, el día de Euskal Herria, el que hemos elegido para alegrar con nuestras canciones todas las casas. Felicidad a todos los moradores de esta casa; venimos a cantar coplas [oles] con la intención de que, nuevamente este año, de puerta en puerta retomemos la vieja tradición. Santa Águeda. Glorifiquemos a Santa Águeda, pues mañana es Santa Águeda: Que en esta casa tengais felicidad para siempre. Santa Águeda" (bis). 
prendas en blanco. Los hombres, preferentemente con txapela ${ }^{12}$. En cuanto a los utensilios accesorios, todos los integrantes de la agrupación llevan los característicos palos para golpear en el suelo marcando el ritmo, así como el farol: uno de los palos de azada, con una vela en la punta, se enciende cuando se canta, no durante todo el recorrido, por la dificultad de mantenerla encendida en la calle, al aire libre. Dicho palo lo lleva uno de los niños que acompana al coro. Hay que destacar en este sentido que el coro, además de los miembros de la agrupación, incluye algunos niños y otras personas, afines a los miembros del coro o a la Euskal Etxea.

La preparación del recorrido fue, en esta primera salida, precipitada, ante la inminencia de la festividad. Finalmente, el recorrido que se preparó fue el descrito a continuación. En primer lugar, la salida del restaurante de la Euskal Etxea. El coro, acompañado por algunos niños, familiares de los miembros de la agrupación, cantó en la puerta del local. Tras la interpetación del tema de Santa Águeda, así como de otros dos temas más, se pasó una txapela por el restaurante y entre la gente que se había parado a escuchar en la calle, obteniendo la primera recaudación de la noche -acompañada por la aportación, más substanciosa, obsequiada por el propio restaurante de la Euskal Etxea, que ofreció, además, a los miembros del coro, unos vasos de vino.

El recorrido continuó seguidamente por el distrito de la Ciutat Vella, deteniéndose el coro y cantando frente a diversos comercios y locales de personas relacionadas de uno u otro modo con la entidad vasca. Se siguió hasta un restaurante vasco cercano, donde se hizo una breve interpretación en el exterior.

Repartidos en varios automóviles de los mismos miembros del coro, llega el momento del cambio de zona. Ya que no se había podido contactar con otros restaurantes vascos, el coro se encaminó hacia el domicilio de los particulares que habían tenido la iniciativa de la actuación. Así, se desplazó hasta el barrio de Las Tres Torres, en el distrito residencial de Sarrià-Sant Gervasi. Ante la primera de las casas particulares, se cantó delante del edificio. Los dueños de la casa bajaron hasta la puerta. Dieron aguinaldo y vino de Rioja ${ }^{13}$ para los adultos y refrescos para los

\footnotetext{
${ }_{12}$ Boina típica vasca, reconocida como indumentaria característica.

${ }^{13}$ El hecho de que se trate de vino de Rioja no es en absoluto banal. En casi todos los casos, las personas que dan el aguinaldo en especie lo han hecho con alimentos típicos vascos o relacionados con el área circundante (Navarra, La Rioja): vino de Rioja (particularmente Rioja alavesa), quesos, chistorra, embutidos típicos, etc. La alimentación viene a reforzar, de este modo, el proceso identitario que rodea la
} 
niños. Seguidamente, el coro se encaminó hacia la siguiente casa. Cantó, igualmente, ante la puerta del edificio, con la familia escuchando en el balcón. Bajó el dueño de la casa a la calle a dar el aguinaldo.

Una informante asistente nos decía al respecto:

- [...] A los que estamos aquí, lo que nos gusta es verlo y mantener aquí las tradiciones de allí.

- [su hija] Yo me acuerdo la última vez que nos vinieron a cantar que tenía unos 10 años. [...] Me hace ilusión, ya ves [...].

(Mujeres, guipuzcoana y barcelonesa de origen vasco, 52 y 28 años, respectivamente)

Tras esta actuación, el coro se dirige hacia el último lugar concertado: Nafarren Etxea, la Casa de los Navarros. Al tratarse de una festividad compartida, la Casa de los Navarros se ofreció a acoger al coro de la Euskal Etxea para que cantase en su local social como última etapa de la noche y aprovechar para llevar a cabo allí una pequeña celebración. El coro canta en primer lugar en el balcón del frontón de pelota vasca, para bajar seguidamente al restaurante de la casa navarra, donde se celebran en ese momento dos cenas con numerosos asistentes. En un principio se iba a cantar sólo en una de las dos reuniones, en la cual habían demandado la actuación del coro, pero en la otra también reclaman otra actuación, consiguiéndose aguinaldo de ambas. Uno de los comensales de la primera de las dos reuniones nos decía:

Esto antes se veía más, porque lo hacían los estudiantes vascos que estaban aquí en Barcelona. Lo digo por mis cuñaos, por ejemplo, que salían a recorrer. Iban por las Ramblas y por ahí arriba ${ }^{14}$ y paraban en cada sitio y se tomaban allí los vinos, y cogían cada una ...

La junta directiva de Nafarren Etxea tiene preparada, como "aguinaldo" para el coro, una mesa, en un salón del restaurante, provista con vino y toda una serie de complementos con los que invitan a los miembros de la agrupación: chistorra, croquetas, buñuelos de bacalao, pimientos del piquillo, etc. En un ambiente ya mucho más distendido y alrededor de la

celebración de la fiesta. En relación al papel del consumo de vino de la tierra propia entre los emigrantes, resulta interesante, como ejemplo comparativo, el artículo de Juan M. Valadés (1994) sobre la importancia concedida a este aspecto entre la emigración extremeña.

${ }^{14}$ Se refiere al barrio de Les Corts, en el distrito IV, también en la zona alta de la ciudad y colindante con el de Sarrià-Sant Gervasi. Este distrito es también muy significativo en relación al número de vascos en él empadronados. 
mesa, los integrantes del coro, acompañados de miembros de la Nafarren Etxea, acaban cantando otras canciones populares vascas y navarras. Alrededor de la media noche, la celebración toca a su fin y los miembros del coro abandonan este último local anfitrión. Uno de los integrantes del coro comentaba al grupo al acabar la celebración:

Para el año que viene hay que preparar algo con cara y ojos; preparar un itinerario bien hecho [...] Pero qué quieres, si total hace unos meses que funcionamos, no se puede pedir más [...].

(Varón, vasco-navarro, 55 años)

Tal como expone la declaración citada de este último informante y siguiendo el ciclo festivo anual, la siguiente celebración de Santa Águeda no llegaría hasta el año siguiente: la noche del 3 de febrero, sábado anterior a la víspera de Santa Águeda. Al igual que el año anterior, días antes se habían pedido los permisos a la guardia urbana de los distritos donde se pretendía cantar: nuevamente, los de Ciutat Vella y Sarrià-Sant Gervasi.

A diferencia del año precedente, en el cual la preparación de la celebración fue bastante más precipitada y la salida, una actividad casi exclusivamente de los componentes del coro, este segundo año la iniciativa se hizo extensiva a todos los socios de la Euskal Etxea, así como a aquellos acompañantes que quisieran añadirse ${ }^{15}$. La respuesta fue relativamente significativa. Además de los integrantes del coro, se añadieron otros acompañantes externos, socios o no de la Euskal Etxea, dando esta vez a la salida un tomo aún más lúdico que en la edición anterior.

Al igual que el año precedente, los integrantes del coro iban vestidos de oscuro y blanco y llevaban los palos de azada con los cuales se golpea el suelo, siguiendo el ritmo, al cantar el tema de Santa Águeda.

El recorrido escogido para esta segunda celebración se inició, de la misma manera, en el restaurante de la Euskal Etxea, donde se cantaron las primeras canciones. Nuevamente, dicho restaurante invitó a vino a los asistentes y dio aguinaldo para el coro. La comitiva inició la marcha hasta llegar a otro conocido restaurante vasco cercano. Tras la interpretación del tema de Santa Águeda -así como de otros conocidos-, y el ofrecimiento de los responsables del restaurante a la comitiva —como aguinal-

\footnotetext{
15 Aunque nuestro trabajo de campo acabó definitivamente en el año 1999, hay que señalar que, hasta el momento actual (2001), la fiesta de Santa Águeda se ha afianzado como celebración, cada vez más abierta a la participación, no únicamente de los socios de la Euskal Etxea, sino de todas aquellas personas - principalmente relacionadas de algún modo con el País Vasco- que han deseado sumarse.
} 
do- de vino y unos pintxos, se continúa camino hacia el siguiente lugar de destino - otra popular taberna-restaurante de la Ciutat Vella-; el grupo, sin embargo, se desvió para pasar, este año por vez primera, por las populares Ramblas ${ }^{16}$ barcelonesas, donde el coro fue cantando y pasando la txapela a la gente que se paraba a escuchar. Siguiendo con el recorrido, los celebrantes llegan al tercero de los locales previstos: una muy popular taberna vasca - propiedad de un conocido cocinero vasco-barcelonés, socio, además, de la Euskal Etxea de Barcelona-, donde invitaron a los asistentes a beber y a unos pintxos.

Tras el recorrido por los bares y restaurantes vascos, así como por las calles del centro de la ciudad, la comitiva se dirigió nuevamente y al igual que el año anterior, hacia el barrio de Las Tres Torres, en el distrito de Sarrià-Sant Gervasi, donde se visitaron dos domicilios particulares, coincidentes con los visitados el año anterior. En ellos se cantó, al igual que en la ocasión precedente, ante el edificio y los dueños de la casa bajaron a la calle, dieron aguinaldo para el coro e invitaron a los asistentes a un pequeño refrigerio. Finalmente, y también al igual que el año anterior, salieron hacia la Casa de los Navarros, donde nuevamente la comitiva fue recibida por miembros de la junta directiva de la entidad y dirigida hacia el restaurante, donde se canta el final de fiesta compartido con los socios de la casa navarra, frente a una mesa bien provista con vinos navarros y pintxos y tapas diversas para "picar", en un ambiente distendido y familiar.

\section{HACIA UNA CONSTRUCCIÓN SIMBÓLICA DEL TERRITORIO}

Uno de los aspectos que considero de una mayor relevancia en lo que respecta a la celebración de Santa Águeda en tanto que ritual es la construcción simbólica del territorio —ulugar de identidad", como señala Marc Augé (1996: 147)— que se lleva a cabo por parte de los miembros del grupo. Dicha construcción espacial que se establece a partir de la creación $\longrightarrow$ reformulación - del ritual festivo es, por lo tanto, particular y simbólicamente significativa. Así, en el caso de la celebración de Santa Águeda podemos comprobar cómo el trayecto que se lleva a cabo recorre diversos aspectos de la vida vasca en la ciudad.

En primer lugar, el punto de partida para la celebración es el local social de la Euskal Etxea; es decir, la casa vasca de Barcelona. El recorri-

${ }^{16}$ Las Ramblas son una de las principales y más conocidas avenidas de la ciudad, corazón sentimental e histórico de la misma. 
do, de este modo ${ }^{17}$, unirá diversos espacios vascos dentro de la ciudad: desde la Euskal Etxea y su restaurante, hasta la hermana Casa de los Navarros, pasando, entretanto, por otros afamados locales de restauración vascos del centro urbano, así como por las populares Ramblas. Además, la celebración de Santa Águeda aporta un aspecto especialmente interesante: introduce en el ritual, no únicamente la vida pública vasca de la ciudad, sino también la privada, los lugares de residencia de los vascos barceloneses. Para ello, el ritual cambia de localización urbana y se traslada a uno de las áreas residenciales más representativas para la migración vasca: el distrito de Sarrià-Sant Gervasi. Finalmente y desde allí, el círculo territorial se cierra y se termina la fiesta -también ritualmente- en la Nafarren Etxea, uniendo de este modo, de manera simbólica, los territorios vas $\cos ^{18}$ de Barcelona en un recorrido mucho más que significativo, construyendo así, a través del ritual, el "territorio vasco" en la diáspora barcelonesa ${ }^{19}$. Como uno de nuestros informantes afirmaba:

"[...] Nos han tratado como en casa. [...] Da gusto [...] celebrar una tradición [...] compartida. Además, aquí son la mayor parte euskaldunes ${ }^{20}$. Ha sido una goza$d a$.

(mujer, guipuzcoana, 52 años) ${ }^{21}$.

En relación a la expresión como en casa, expuesta por la informante, y siguendo la definición de Hannerz (1998), podemos observar que el estar en casa $\longrightarrow$ el sentirse como en casa- implica, por un lado, un lugar donde los elementos culturales que rodean al individuo sean habituales y compartidos, cercanos y practicables/utilizables, un lugar donde "todo parece sencillo y directo"; pero, por otro lado, y principalmente, "un lugar cómodo, de caras familiares; un lugar donde la mayoría de los otros son personas locales. Es, en cierta forma, aquello que el sociólogo Michel Maffesoli (1990) llamaría el "estar juntos", un lugar de proxemia. La sensa-

17 Tomamos como pauta más definitiva el recorrido llevado a cabo en la segunda de las celebraciones, una vez que el ritual se encuentra ya más asentado y el recorrido parece haberse establecido de una manera más firme.

${ }^{18}$ Cf. también en este sentido Medina (1997b).

19 Una construcción del territorio que puede ser observada también en relación a otros aspectos sociales construidos y llevados a cabo por el grupo en cuestión, como es el caso del deporte. He tratado este tema en un artículo anterior (Medina, 1997).

${ }^{20}$ Euskaldun: persona vascohablante; frecuentemente, y por extensión, se utiliza también para referirse a los vascos en general.

${ }^{21}$ Declaración recogida al final de la segunda de las celebraciones de Santa Águeda. Las cursivas son mías. 
ción de estar como en casa forma, pues, parte de una simbiosis particular entre los actores y el medio en cuestión, construido, en este caso, también simbólicamente por medio del ritual.

Señalaba Julio Caro Baroja (1991: 78) que, mientras existe un ritual o una actividad, no es nunca una supervivencia, sino una vivencia: "muchos ejemplos de lo que llamaban supervivencias, mejor observados, no lo son. Otros no se pueden considerar sólo desde un punto de vista lógico o utilitario: la persistencia cultural no es por fuerza una supervivencia, sino una pura vivencia, con duración larga y complicada: lo que queda absolutamente sin sentido pervive poco. Porque, por otra parte, hay ritos, costumbres, etc., que tienen o pueden tener sentidos estéticos, emocionales, etc. que los antropólogos evolucionistas antiguos tuvieron poco en cuenta. Tampoco otros más modernos". Con relación al ritual que nos ocupa, creemos que no hay ningún tipo de duda de que la celebración de Santa Águeda es una "vivencia" en el sentido señalado por Caro Baroja. No se trata, por un lado, ni de una "supervivencia" de un ritual vasco, ya que, se mire como se mire, tanto los actores -de muy distintas procedencias dentro del País Vasco, o incluso de fuera de él- como el medio en el que se lleva a cabo - Barcelona, la diáspora ${ }^{22}$ - no son los mismos que cualquier celebración de estas características que pueda darse en el propio Euskadi; ni, por otro lado, se trata de un ritual "trasplantado" de uno a otro territorio, ya que la recreación en la diáspora de dicho ritual exige un replanteamiento de su desarrollo, tal como hemos podido observar, y una construcción particular del territorio, elaborada de manera simbólica por los actores mismos. De este modo, la celebración de Santa Águeda reconstruye y reformula reinventa, en definitiva- una tradición.

Señala Delgado (1998: 121) en relación a este tema que "las tradiciones aparecen en momentos en que a las comunidades humanas les cuesta hacer compatible la necesidad de puntos de referencia estables en su sistema del mundo y los cambios rápidos o bruscos en la vida social. Aquí es el requerimiento psicológico de anclajes el que propicia la aparición de falsas tradiciones, destinadas a producir la impresión de cierta continuidad inalterable en una vorágine de innovaciones como las que implica la vida modernan. Sin embargo, hay que matizar que desde nuestra perspectiva, y en tanto en cuanto se trata de un producto sociocultural, elaborado por un grupo, no nos atreveríamos jamás a tachar de "falsa

${ }^{22}$ Sobre la formación de la diáspora vasca, cf. Douglass (1997). También Medina (1997c). 
tradición" 23 el ritual de Santa Águeda, ya que, para los propios actores, este no es un ritual nuevo, sino, por el contrario, de amplia raigambre en el País Vasco. Como expresaba una de nuestras informantes:

Santa Águeda la he vivido yo desde pequeña... toda mi vida.

(Mujer, vizcaína, 74 años)

No se trata tampoco, por otro lado, como hemos mencionado anteriormente, de un ritual trasplantado al lugar de residencia, en tanto en cuanto ni los actores, ni el medio, ni el contexto son los mismos que los existentes en Euskadi. Se trata, en este sentido, de una recreación, por parte de los actores implicados, de un ritual existente en las localidades de origen de los protagonistas, en el cual se toma como referencia el modelo que se conoce - que se ha vivido, que se recuerda- en el País Vasco, reproduciéndolo, aunque únicamente con los actores presentes y en un territorio distinto. No se trata, pues, ni de una "invención" ni de un ritual "trasplantado", ya que no recoge tampoco una estructura exacta preexistente en otro lugar, sino que "recrea" el ritual, adaptándolo sobre el terreno en base a las nuevas posibilidades y necesidades de la acción grupal.

En este sentido, el ritual festivo es simbólicamente útil - una vivencia, en palabras de Caro Baroja- y ejerce su función de construir un espacio "propio" y significativo para el grupo, que sirve, desde esta misma perspectiva, como pauta y referencia en la construcción social del nosotros en términos de una etnicidad específica vasca en la diáspora.

\section{BIBLIOGRAFÍA CITADA}

AMADES, JOAN. 1982. Costumari català. El curs de l'any. Vol. I. Barcelona: Salvat/Edicions 62.

AugÉ, MARC. 1996. Hacia una antropología de los mundos contemporáneos. Barcelona: Gedisa.

Caro Baroja, Julio. 1991. Los fundamentos del pensamento antropológico moderno. Madrid: CSIC.

Delgado, Manuel. 1998. Diversitat i integració. Barcelona: Empúries.

\footnotetext{
${ }^{23}$ Las "falsas tradiciones" a las que se refiere Delgado en su cita son aquellas directamente inventadas $-\mathrm{y}$, por lo tanto, de muy reciente creación- por un colectivo y camufladas entre referentes históricos significativos para la comunidad. Este hecho no impide, sin embargo, que su efectividad simbólica y representativa, de cara a la comunidad en cuestión, no sea $\multimap$ pueda llegar a ser con el tiempo- alta ni significativa.
} 
DOUGLASS, William A. 1997. "Factores que intervienen en la formación de la diáspora emigrante vasca al Nuevo Mundo", en F. Xavier Medina (comp.), Los otros vascos. Las migraciones vascas en el siglo XX: 27-49. Madrid: Fundamentos.

HANNERZ, UlF. 1998. Conexiones transnacionales. Cultura, gente, lugares. Madrid: Cátedra.

HOYOS, NIEves DE. 1951. "Fiesta en honor de Santa Águeda, patrona de las mujeres". RDTP VII: 446-456.

JOCILES, M.a ISABEL. 1992. Niños, mozos y casados a través de sus fiestas en La Rioja. Logroño: Instituto de Estudios Riojanos.

Laburu, Jon Gozton y M.a CARmen BazA. 1995. Santa Águeda y sus tradiciones. VitoriaGasteiz: Diputación Foral de Álava/Arabako Foru Aldundia.

LÓPEZ DE GUEREÑU, GERARDO. 1988. Refranero alavés. Vitoria-Gasteiz: Diputación Foral de Álava/Arabako Foru Aldundia.

MAFFESOLI, MiCHEL. 1990. El tiempo de las tribus. Barcelona: Icaria.

MEDINA, F. XAVIER. 1997. "Nuevos rituales deportivos urbanos y construcción de la etnicidad. La Korricursa de Barcelona", en R. Sánchez (ed.), La actividad física y el deporte en un contexto democrático (1976-1996). Pamplona: AEISAD.

- 1997b. "La inmigración vasca en la ciudad de Barcelona. Una aproximación desde la antropología urbana", en F. Xavier Medina (comp.), Los otros vascos. Las migraciones vascas en el siglo XX: 173-187. Madrid: Fundamentos.

- 1997c. "Emigrantes y emigrados. Las migraciones vascas en el siglo XX", en F. Xavier Medina (comp.), Los otros vascos. Las migraciones vascas en el siglo XX: 15-26. Madrid: Fundamentos.

- 2000. "Migraciones en un contexto urbano. Un estudio comparativo de las inmigraciones vasca y andaluza en Barcelonan. Zainak. Cuadernos de Sección de Antropología-Etnografia 19.

ROMA, JoSEFINA. 1989. "La Candelera, Sant Blai i Santa Àgata", en D. Llopart; J. Prat; J. Roma; P. Font y A. Pons (dirs.), Calendari de festes de Catalunya, Andorra i la Franja. Barcelona: Alta Fulla/Serveis de Cultura Popular.

VALADÉS, JUAN M. 1994. "El vino de nuestra tierra. La tendencia al consumo de vinos otros productos regionales entre los emigrados extremeños", en XVI Jornadas de Viticultura y Enología de Tierra de Barros. Badajoz: Junta de Extremadura.

VorÁGINE, JACOBO DE LA. 1982. La leyenda dorada. Madrid: Alianza. 